\title{
Comunicación
}

\section{Piometra y Tumor de Sertoli en un Canino con Conducto de Müller Persistente}

\author{
Pyometra and Sertoli Cell Tumor in a Dog with Persistent Müller Duct
}

\author{
Jacqueline Cahua U. ${ }^{1,3}$, Nieves Sandoval C. ${ }^{2}$, Víctor Fernández A. ${ }^{1}$, Víctor Puicón N. ${ }^{1}$
}

\section{Resumen}

La persistencia del conducto de Müller (PMDS) es un tipo de seudohermafroditismo masculino hereditario que se ha registrado en varias razas de canes, donde los machos presentan testículos, cromosomas XY, además de oviducto, útero y vagina craneal como derivados de los ductos müllerianos. Se describe el caso de un canino Schnauzer fenotípicamente macho de 8 años de edad, con antecedentes de inapetencia, letargia y tenesmo desde los dos últimos días. La mascota presentaba órganos genitales masculinos pero evidenciaba criptorquidia lateral derecha. El examen ecográfico reveló esbozos del conducto de Muller (cuernos uterinos y cuerpo del útero) con un proceso infeccioso compatible con piometra. En el frotis sanguíneo se observaron células polimorfonucleares sin corpúsculos de Barr. Por otro lado, se encontró una masa tumoral craneal al cuerno uterino derecho correspondiendo a una neoplasia testicular de las células de Sertoli. El testículo izquierdo, ubicado en el saco escrotal, estaba hipoplásico.

Palabras clave: conducto de Müller persistente, piometra, tumor de Sertoli

\section{Abstract}

Persistent Mullerian duct (PMDS) is a type of hereditary male pseudohermaphroditism observed in several dog breeds. Males have testes and XY chromosomes in addition to oviduct cranial vagina, uterus and bilateral Müllerian duct derivatives. In the present study is described the case of a 8-year Schnauzer dog, phenotypically male, with a history of anorexia, lethargy and tenesmus during the last two days. The pet had male genitalia but evident right lateral cryptorchidism; however, ultrasound examination

${ }^{1}$ Clínica de Animales Menores, ${ }^{2}$ Laboratorio de Histología, Embriología y Patología Veterinaria, Facultad de Medicina Veterinaria, Universidad Nacional Mayor de San Marcos, Lima, Perú

${ }^{3}$ E-mail: jackiecahua@gmail.com

Recibido: 28 de enero de 2015

Aceptado para publicación: 28 de mayo de 2015 
revealed that the animal had remnants of the duct Muller (uterine body and horns) with an infectious process compatible with pyometra. The blood smear showed polymorphonuclear cells without corpuscles of Barr. A tumor mass was found cranial to the right uterine horn and corresponded to a testicular neoplasia of Sertoli cells. The left testicle was located in the scrotal sac and was hypoplastic.

Key word: persistent Mullerian duct, pyometra, Sertoli cell tumor

\section{INTRODUCCIÓN}

En los mamíferos, el desarrollo sexual depende de una serie de mecanismos que se hallan bajo control génetico. Estos procesos consisten en el establecimiento del sexo cromosómico, sexo gonadal y fenotipo sexual. Los individuos que presentan alteraciones de estos mecanismos se conocen como seudohermafroditas machos o hembras. Los seudohermafroditas machos son cromosómicamente XY, presentan testículos bilaterales y cierto grado de genitalidad de hembras. En estos casos se pueden establecer dos etiologías: falla en la regresión del conducto de Müller y falla en la masculinización andrógena dependiente.

El síndrome de la persistencia del conducto de Müller (PMDS) se ha registrado en perros de las razas Schnauzer y Basset Hound y en gatos persas (Meyers-Wallen, 2001). Los Schnauzer miniatura afectados presentan oviductos, cuernos uterinos, útero, cérvix y vagina craneal, siendo criptorquídeos cerca de la mitad de ellos. El PMDS parece heredarse en esa raza como un carácter autosómico recesivo con expresión limitada a machos XY. Los embriones afectados producen una sustancia inhibidora mülleriana (MIS) durante el periodo de regresión del conducto de Müller (Hare, 1976).

\section{Caso Clínico}

Un canino Schnauzer de 8 años de edad, $9 \mathrm{~kg}$ de peso vivo, de la ciudad de Lima, fue remitido a la Clínica Veterinaria de Animales Menores de la Universidad Nacional Mayor de San Marcos (UNMSM) con historia de inapetencia, tenesmo y letargia desde hace dos días. En el examen clínico se evidenció inflamación escrotal, moderada inflamación erosiva perianal, dolor abdominal y cervical, así como hemorragias focalizadas cutáneas y en la esclerótica. Se solicitó exámenes hematológicos, bioquímicos y ecográficos.

El examen ecográfico reveló una nefrosis moderada bilateral pero con diferenciación corticomedular conservada y cuernos uterinos con evidencia de abundante colección líquida hipoecogénica, compatible con piometra (Fig. 1). Un segmento de uno de los cuernos uterinos se encontraba en el saco escrotal izquierdo, pero no se evidenció el testículo. Además, se observó una masa tumoral heterogénea de $72.3 \mathrm{~mm}$ de longitud, $47.8 \mathrm{~mm}$ de espesor y $74 \mathrm{~mm}$ de diámetro transverso, ubicado a nivel de la zona lumbar. La glándula prostática presentaba parénquima y morfología conservada.

El examen hematológico reveló lo siguiente: $36 \%$ hematocrito, $5.2 \times 10^{6} / \mathrm{ml}$ eritrocitos, $11.6 \mathrm{~g} / \mathrm{dll}$ hemoglobina, $490 \times 10^{3} / \mathrm{\mu l}$ glóbulos blancos, 16 000/ $\mu$ l plaquetas, desviación a la izquierda degenerativa (hipoplasia de médula ósea), así como abastonados ++, vacuolización citoplasmática +++ y basofilia citoplasmática ++ . El examen bioquímico mostró $45 \mathrm{mg} / \mathrm{dl}$ urea, y $2 \mathrm{mg} / \mathrm{dl}$ creatinina y $26 \mathrm{UI} / \mathrm{L}$ ALT.

Con base a los exámenes realizados, se le indicó al dueño la opción quirúrgica para la 


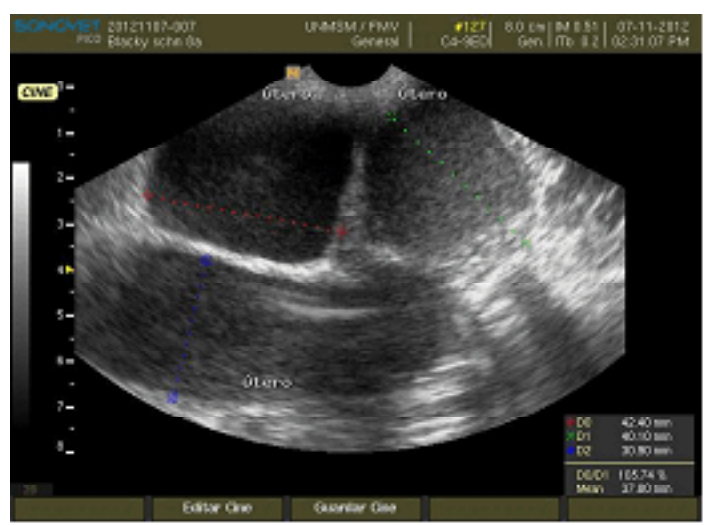

(a)

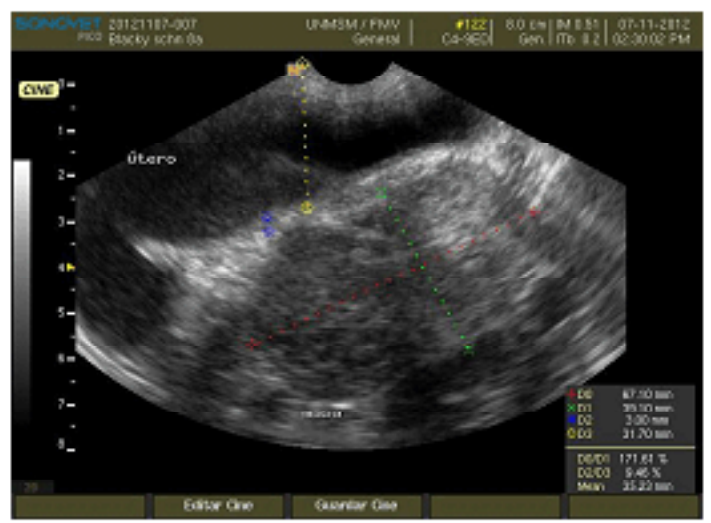

(b)

Figura 1. Imágenes ecográficas de un perro Schnauzer de 8 años de edad, fenotípicamente macho. (a) Se observan cuernos uterinos dilatados con abundante colección hipoecogénica, compatible con piometra, (b) Se observa un tumor de Sertoli (67.1 x $39.1 \mathrm{~mm}$ ), como una masa parenquimatosa, heterogénea, nodular, de bordes definidos. En el campo cercano se puede observar un cuerno uterino dilatado en corte longitudinal.

extirpación uterina y tumoral. En la cirugía se observó un testículo pequeño en el saco escrotal izquierdo, unido al cuerno uterino izquierdo que medía 12 x $2.5 \mathrm{~cm}$. La masa derecha de forma nodular presentaba una dimensión de $7.8 \times 6.5 \mathrm{~cm}$, unida cranealmente al cuerno uterino derecho de $16 \times 3 \mathrm{~cm}$ (Fig. 2). El cuerpo del útero medía $5 \mathrm{~cm}$ de largo y $3.5 \mathrm{~cm}$ de diámetro y se relacionaba a la próstata caudalmente. La mucosa endometrial se encontraba hemorrágica. El líquido uterino era de coloración blanquecina y de aspecto lechoso. Muestras de testículo izquierdo, útero y de la masa nodular se remitieron al Laboratorio de Patología Veterinaria de la UNMSM.

Se realizó un examen hematológico posterior a la intervención quirúrgica, que reveló la ausencia de los corpúsculos de Barr en los polimorfonucleares. Además, se realizó un examen citológico al líquido uterino, encontrándose la presencia de abundantes neutrófilos degenerados y células descamadas.
El testículo izquierdo se encontraba en estado inmaduro. El parénquima, compuesto de túbulos seminíferos inmaduros separados por moderado intersticio, células germinales como espermatogonias, algunas células alargadas, elongadas y muy escasas, compatibles con células de Sertoli poco diferenciables. En la hilera superior, células semejantes a espermatocitos tipo I y una gran luz cubierta con abundante contenido proteináceo con ausencia de espermatozoides. A nivel del intersticio, células con escaso pigmento marrón y escasa presencia de linfocitos. Se diagnosticó como hipoplasia testicular.

En el corte de útero se evidenciaba epitelio cúbico, que en algunas zonas generaban estratos que se hallaban degenerados, y en la submucosa se observaron abundantes acinos glandulares de diverso tamaño y abundantes vasos sanguíneos, los cuales presentaban una severa dilatación. En algunos campos se observó infiltración de neutrófilos a nivel de la submucosa. En zonas más profundas, las ca- 


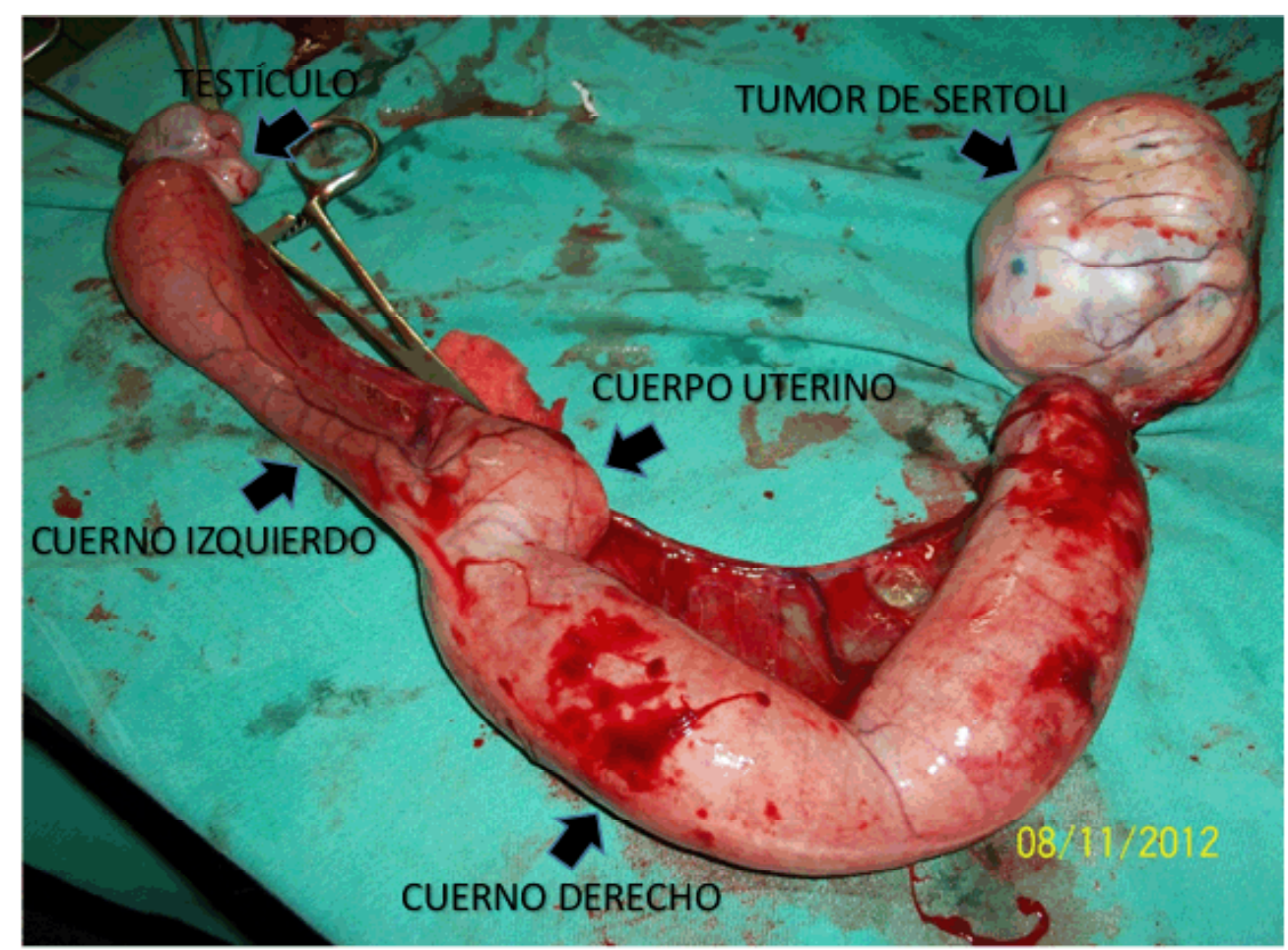

Figura 2. Cuernos uterinos dilatados y llenos de material purulento, de un perro Schnauzer de 8 años de edad, fenotípicamente macho. En el extremo superior derecho del cuerno uterino se observa el tumor de Sertoli. En el extremo izquierdo del otro cuerno uterino se encuentra el testículo hipoplásico. La pinza hemostática se encuentra en el cuerpo uterino.

pas musculares estaban engrosadas y con múltiples vasos sanguíneos dilatados y con presencia de células inflamatorias en su interior. La capa muscular presentaba zonas degeneradas, disgregadas y con evidencia de fibras, con 2 a 3 nucléolos prominentes, y algunos núcleos de forma arriñonada, ovalados o redondos, de bordes romos.

En uno de los cuernos uterinos se observó ausencia de epitelio endometrial, con capa muscular, vasos sanguíneos y células semejantes al otro cuerno uterino. Las fibras musculares corrían en distintas direcciones de forma desordenada. A diferencia del otro cuerno uterino, el epitelio estratificado de la mucosa intentaba formar una incipiente metaplasia queratinizada. En la submucosa se observó infiltración de células inflamatorias de tipo neutrófilos y evidencia de angiogénesis.
Había detritus celulares, glóbulos rojos, células descamadas, neutrófilos degenerados y lisados en la luz del corte de ambos cuernos uterinos. Debido a la presencia del exudado en todas las capas del útero y a los cambios observados, se concluyó que era una severa metritis supurativa difusa crónica con metaplasia queratinizada.

La histopatología de la masa nodular, que se encontraba craneal al cuerno uterino derecho, demostró ser una neoplasia de células de Sertoli, la cual presentaba múltiples túbulos separados por abundante tejido conectivo fibroso. Las células que componían los túbulos eran elongadas, alargadas y dispuestas en empalizada de múltiples nucléolos de distintos tamaños y formas, con cromatina dispersa e hipocromática. La mayoría se unía con las células opuestas obliterando la luz del túbulo, no evidencián- 


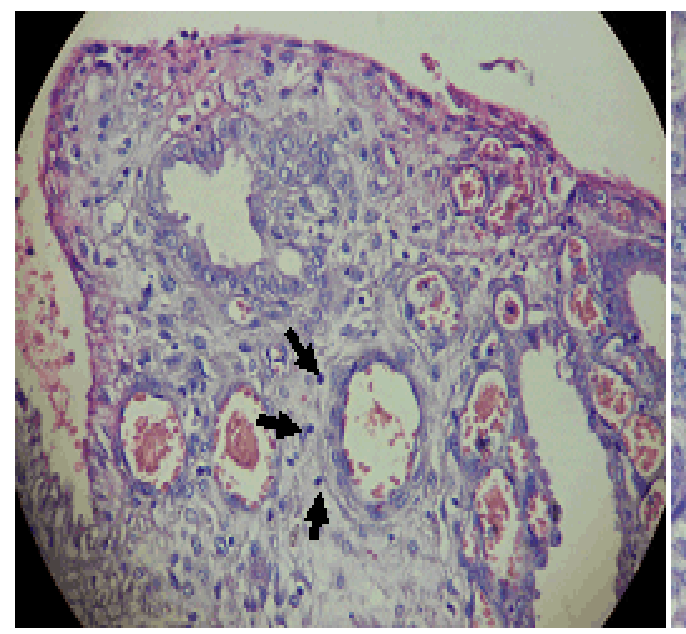

(a)

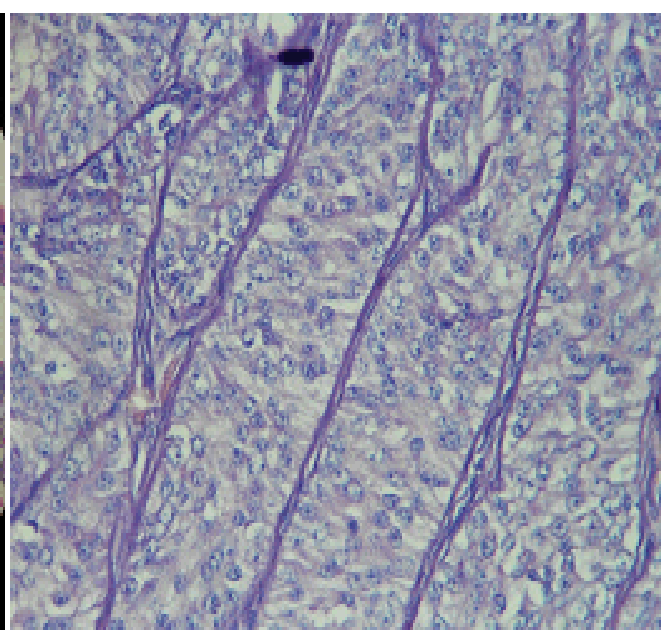

(b)

Figura 3. (a) Útero: sección de corte de pliegue endometrial, donde se observa hiperplasia del epitelio, dilatación de las glándulas, proliferación de la vascularización y células inflamatorias (flechas); (b) Tumor de Sertoli: sección de corte de testículo derecho. Se observan células elongadas, piramidales, dispuestas en empalizada y núcleos grandes con cromatina dispersa $(400 \mathrm{x})$

dose otro tipo celular propio del túbulo seminífero testicular.

Debido a la presencia de hemorragias cutáneas focalizadas, se optó por realizar un descarte de Ehrlichia canis, el cual fue negativo.

Al cuarto día posterior a la cirugía se observó una disminución de la presencia de hematomas y hemorragia en la esclerótica y aumentó el apetito. El hemograma practicado al sétimo día de la cirugía indicó $20.7 \%$ hematocrito, $2.9 \times 10^{6} / \mathrm{ml}$ eritrocitos, $6.19 \mathrm{~g} / \mathrm{dl}$ hemoglobina, $4730 \times 10^{3} / \mu 1$ glóbulos blancos, $37000 / \mu 1$ plaquetas. La mascota recibió el alta al día siguiente.

\section{Discusión}

En este caso, el animal, fenotípicamente, corresponde al sexo macho, con órganos externos masculinos, aunque con evidencia de una criptorquidia lateral derecha. En el exa- men hematológico se evidenció ausencia de corpúsculos de Barr en las células polimorfonucleares, y en el examen ecográfico se encontraron restos del desarrollo del conducto de Müller (cuernos uterinos y cuerpo del útero), de allí que el diagnóstico sea de seudohermafroditismo masculino. Los dueños no observaron alteraciones en el comportamiento sexual del perro.

Los seudohermafroditas machos son cromosómicamente $\mathrm{XY}$ y pueden ocurrir ante una falla en la regresión del conducto de Müller o ante una falla en la masculinización andrógeno dependiente. En este último caso, se sabe que hay una regresión completa del conducto de Mülller (Meyers, 1999), de allí que el presente caso clínico correspondería al llamado síndrome de la persistencia del conducto de Müller (PMDS).

El defecto molecular causante de PMDS en el Schnauzer miniatura es una transición de C a T (C241T) en el exón 3 del gen receptor de la sustancia antimülleriana tipo 
II, MISRII (AMHR2) (Parker et al., 1999; Wu et al., 2009). Meyers-Wallen et al. (1989) ya habían demostrado que el PMDS en esta raza es heredado como un rasgo autosómico recesivo, con expresión limitada a machos homocigotos.

La presentación del cuadro de piometra en el paciente pudo deberse a una contaminación bacteriana ascendente desde la uretra prostática, considerando que MeyersWallen et al. (1989) reportaron una conexión entre la vagina craneal y la uretra prostática.

El riesgo de desarrollar un tumor de células de Sertoli en testículos criptórquidos es 6-13\% mayor que en los escrotales (Sanpera et al., 2002). El desarrollo tumoral testicular probablemente se ve influenciado por el incremento de la temperatura abdominal que destruye las células espermatogénicas, dejando a las células de Sertoli tumorales libres para desarrollarse (Okjin y Kyung-Suk, 2005).

La anemia moderada, con severa trombocitopenia y severa leucopenia, y los hematomas en piel y hemorragia a nivel de la esclerótica podrían deberse a un hiperestrogenismo ocasionado por el tumor de Sertoli del testículo derecho. El hiperestrogenismo puede provocar supresión de la médula ósea, caracterizándose por anemia, trombocitopenia y leucopenia, y algunos de los síntomas clínicos pueden estar relacionados a anemia o hemorragia debida a la trombocitopenia (Nelson y Couto, 2010). Del 10 a 15\% de los pacientes con tumor testicular de células de Sertoli presentan supresión de la médula ósea (Merchant, 2005). En algunos casos existe una supresión temporal de la médula, mientras que otras veces se desarrolla una aplasia más severa (Withrow, 2001).

En el presente caso, luego de la cirugía se observó un aumento en el recuento de glóbulos blancos y de plaquetas, que se debería al hecho de haberse eliminado la fuente de estrógenos proveniente del tumor de Sertoli.
Se ha descrito un aumento de la linfopoyesis $\mathrm{T}$ y $\mathrm{B}$ y de la producción de células B esplénicas en ratas ovariectomizadas que regresiona con tratamiento de estradiol (Erben et al., 1998; Benayahu et al., 2000). También se ha descrito en perros que los estrógenos inducen la producción de un factor inhibidor de la mielopoyesis, por el cual se produciría la depresión de la médula ósea (Farris y Benjamin, 1993). Asimismo, se pudo observar que el hematocrito disminuyó después del primer examen, lo cual pudo deberse a la pérdida de sangre durante la cirugía, ya que se observaron hematomas subcutáneos en el flanco y perianales, además de una hemorragia episcleral.

Ecográficamente, el tumor de células de Sertoli no se puede diferenciar entre otros tipos de tumores testiculares y, por lo tanto, se requiere un estudio histopatológico.

\section{Literatura Citada}

1. Benayahu D, Shur I, Ben-Eliyahu S. 2000. Hormonal changes affect the bone and bone marrow cells in a rat model. $\mathrm{J}$ Cell Biochem 79: 407-415. doi: 10.1002/ 1097-4644(20001201)79:33.0.CO;2-8

2. Erben RG, Raith S, Eberle J, Stangassinger M. 1998. Ovariectomy augments B lymphopoiesis and generation of monocyte-macrophage precursors in rat bone marrow. Am J Physiol 274: 476-483.

3. Farris GM, Benjamin SA. 1993. Inhibition of myelopoiesis by serum from dogs exposed to estrogen. Am J Vet Res 54: 1374-1379.

4. Hare W. 1976. Intersexuality in the dog. Can Vet J 17: 7-15.

5. Kim O, Kim KS. 2005. Seminoma with hiperestrogenemia in a Yorkshire Terrier. J Vet Med Sci 67: 121-123.

6. Merchant S. 2005. The skin as a sensor of internal medical disorders. En: Ettinger S, Feldman E (eds). Textbook of veterinary internal medicine. $6^{\text {th }}$ ed. 
Philadelphia, USA: WB Saunders. p 3133.

7. Meyers-Wallen VN, Donahoe PK, Ueno S. Manganaro T. Patterson D. 1989. Mullerian inhibiting substance is present in testes of dogs with persistent Mullerian duct syndrome. Biol Reprod 41:881-888.

8. Meyers-Wallen VN. 2001. Anormalidades heredadas del desarrollo sexual en perros y gatos. IVIS. [Internet]. Disponible en: http://www.ivis.org/advances/ concannon/meyers_es/ivis.pdf

9. Nelson R, Couto G 2010. Medicina interna de pequeños animales. $4^{\mathrm{a}} \mathrm{ed}$. España: Elsevier. $1467 \mathrm{p}$.

10. Okjin K, Kyung-Suk K. 2005. Seminoma with hyperesterogenemia in a Yorkshire Terrier. J Vet Med Sci 67: 121-123. doi : $10.1292 /$ jvms.67.121

11. Parker KL, Schimmer BP, Schedl A. 1999. Genes essential for early events in gonadal development. Cell Mol Life Sci 55: 831-838.

12. Sanpera N, Masot N, Janer M, Romeo $C$, de Pedro R. 2002. Oestrogeninduced bone marrow aplasia in a dog with a Sertoli cell tumour. J Small Anim Prac 43: 365-369.

13. Wu X, Wan S, Pujar S, Haskins M, Schlafer D. 2009. A single base pair mutation encoding a premature stop codon in the MIS type II receptor is responsible for canine persistent Müllerian duct syndrome. J Androl 30: 46-56. doi: 10.2164/jandrol.108.005736 